\title{
Elective neck irradiation in the management of esthesioneuroblastoma: a systematic review and meta- analysis*
}

\author{
Armando De Virgilio 1,2, Andrea Costantino 1,2, Daniela Sebastiani', \\ Elena Russo 1,2 Ciro Franzese 1,3, Giuseppe Mercante ${ }^{1,2}$, Marta Scorsetti ${ }^{1,3}$, \\ Giuseppe Spriano ${ }^{1,2}$
}

' Department of Biomedical Sciences, Humanitas University, Pieve Emanuele, Milan, Italy

${ }^{2}$ Otorhinolaryngology Unit, IRCCS Humanitas Research Hospital, Rozzano, Milan, Italy

${ }^{3}$ Radiotherapy Unit, IRCCS Humanitas Research Hospital, Rozzano, Milan, Italy
Rhinology 59: 0, 0 - 0, 2021

https://doi.org/10.4193/Rhin21.139

*Received for publication:

April 17, 2021

Accepted: June 20, 2021

\begin{abstract}
Background: There is no consensus about the optimal management of the neck in clinically node negative esthesioneuroblastoma (ENB). The aim of this study is to assess the impact of elective neck irradiation (ENI) in terms of regional disease control and survival.

Methods: The study was performed according to the PRISMA guidelines searching on Scopus, PubMed/MEDLINE, and Google Scholar databases. The primary outcome was the regional recurrence rate (RRR), that was reported as odds ratio (OR) and $95 \%$ confidence interval (CI). Secondary outcomes were the overall survival (OS), and the distant-metastases free survival (DMFS), that were reported as logarithm of the hazard ratios (logHRs) and 95\% confidence intervals (Cls).
\end{abstract}

Results: A total of 489 clinically node negative patients were included from 9 retrospective studies. ENI significantly reduced the risk of regional recurrence compared to no treatment. No difference was measured between ENI and observation, according to both OS and DMFS. No stratified analysis could be performed based on Kadish stage and Hyams grade.

Conclusions: ENI should be recommended to improve the regional disease control. No advantage was measured in terms of survival or distant metastases with a low quality of evidence. Further prospective studies should be designed to understand if ENI could be avoided in early stage and low-grade tumors.

Key words: lymph node, olfactory neuroblastoma, radiotherapy, regional recurrence, survival

\section{Introduction}

Esthesioneuroblastoma (ENB), also named olfactory neuroblastoma, is a rare malignant neoplasm that arises from the olfactory epithelium. ENB represents only $3 \%$ to $6 \%$ of all cancers in the nasal cavity and paranasal sinuses, but the true incidence is rising due to an increase in detection by histopathologic examination through immunohistochemistry, electron microscopy, and molecular investigations ${ }^{(1-3)}$.

Surgical resection remains the mainstay of treatment for ENB, and postoperative radiotherapy is often employed at the primary site for advanced stage tumors to improve local control rate $^{(4,5)}$. Although the clinical manifestations of the disease are usually related to the primary tumor, cervical node metastases are a common finding during tumor staging and follow-up ${ }^{(6)}$. In particular, several reports analyzed the rate of regional metastases which was reported to be up to $20-25 \%$ in large case series ${ }^{(7)}$. However, only a minority of patients (5-12\%) have a clinically $\mathrm{N}+$ classification at diagnosis, while the majority of cervical metastases occurs six or more months after primary treatment. This has been demonstrated by a previous meta-analysis ${ }^{(8)}$. Notably, the development of regional recurrence is strongly associated with mortality based on current literature data ${ }^{(7,9-11)}$. Even if the importance of regional disease control is clear, there is no consensus about the optimal management of the neck in clinically node negative ENB ${ }^{(2,12)}$. The real benefit of an elective surgical or non-surgical treatment of the neck is still to be demonstrated, 
and further data are needed to definitively recommend it. The aim of the present systematic review and meta-analysis is to analyze the role of elective neck irradiation (ENI) in clinically node negative ENB. In particular, we aimed to measure the reduction of regional recurrence rate in patients who underwent $\mathrm{ENI}$, and the potential benefit of this treatment in terms of survival.

\section{Materials and methods}

The study was performed according to the Preferred Reporting Items for Systematic Reviews and Meta-Analyses (PRISMA) guidelines $^{(13)}$. Institutional review board approval and informed consent were not required for this review of previously published studies. No review protocol was registered for this study.

\section{Eligibility criteria}

This systematic review was conducted according to PICOS acronym: Patients $(P)$, patients suffering from clinical node negative (NO) ENB; Intervention (I), elective neck irradiation; Comparator $(\mathrm{C})$, observation; Outcomes $(\mathrm{O})$, regional recurrence rate (RRR), overall survival (OS), and distant-metastases free survival (DMFS); Study design (S), retrospective and prospective cohort studies. Studies were excluded if they (a) were not in English, (b) were not available in full text form, (c) reported insufficient data or data was not extractable, (d) included patients who underwent previous neck dissection, (e) included less than 5 patients who underwent $\mathrm{ENI}$, (f) were subgroup analysis of patients from a larger study, or (g) the article type was either review, case report, conference abstract, letter to the editor, or book chapter. No publication date, or publication status restrictions were imposed, but articles had to be published in a peer-reviewed journal.

\section{Data source and study searching}

Scopus, PubMed/MEDLINE, and Google Scholar databases were searched for relevant publications. Relevant keywords, phrases, and medical subject headings ( $\mathrm{MeSH}$ ) terms were used according to each database requirements. An example of a search strategy was the one used for PubMed/MEDLINE: ("esthesioneuroblastoma" OR "olfactory neuroblastoma") AND ("cervical lymphadenopathy" OR "cervical metastasis" OR "neck metastasis" OR "neck lymphadenopathy" OR "neck salvage" OR "neck management" OR "elective neck dissection" OR "neck dissection" OR "neck irradiation" OR "elective neck irradiation"). The searches in the remaining databases were adjusted to fit the specific requirements for each of the individual databases. The "cited by" function on Google Scholar was used to identify additional articles. Finally, a cross-reference search of the selected articles was performed to minimize the risk of missing relevant data. The last search was performed on March 5, 2021.

\section{Data collection process}

Two independent authors (D.S. and A.C.) separately conducted the electronic search. All articles were initially screened for relevance by title and abstract, obtaining the full-text article if the abstract did not allow the investigators to assess the defined inclusion and exclusion criteria. The two investigators separately reviewed the abstract of each publication and then performed a close reading of all papers to minimize selection bias and errors. A third author (A.D.V.) resolved any conflict between reviewers. Data extraction from the included studies was systematically done using a structured form. In particular, one author (D.S.) independently compiled a standardized form to extract the following characteristics of included studies: study design, number of patients, patient demographics, tumor staging, duration of follow-up, treatment protocols, and main outcomes. This was then checked for accuracy by another author (A.C.).

\section{Risk of bias and study quality assessment}

Methodological quality of included studies was assessed independently by two separate authors (D.S. and A.C.). The National Institute for Health and Clinical Excellence (NICE) quality assessment tool was used to evaluate the quality of the included studies $^{(14)}$. A funnel plot was created using the effect size of RRR to examine for a potential publication bias.

Data synthesis and statistical analysis The data from each study were transcribed in tabular form. Categorical variables were summarized by counts and percentage, while continuous variables were reported as median \pm interquartile range (IQR: 25th and 75th). Clinical measures were reported as provided by the individual studies. Cochran's $Q$ method was used to assess between studies heterogeneity. 12 was calculated as a measure of heterogeneity ${ }^{(15)}$. The $I^{2}$ value represents the percentage of total variation across studies caused by heterogeneity rather than by chance. According to the Cochrane criteria, values from $0 \%$ to $40 \%$ may signify low heterogeneity, $30 \%$ to $60 \%$ may represent moderate heterogeneity, $50 \%$ to $90 \%$ may represent substantial heterogeneity, and $75 \%$ to $100 \%$ represents considerable heterogeneity. Using a fixed effects model, we assumed that all studies came from a common population and that the effect size is not significantly different among the different trials. If the heterogeneity test produced a low probability value $(\mathrm{Q}$-statistic, $\mathrm{p}<0.05)$, then a more conservative random effects model was used.

The odds ratios of RRR and their $95 \%$ confidence intervals (Cls) were calculated for each study. The Mantel-Haenszel method was used to calculate the pooled effect estimate. Inverse variance method (DerSimonian-Laird estimator) was used to estimate the between-study variance $\left(\tau^{2}\right)^{(16)}$. A minimal correction factor of 0.1 was used for " 0 " events to reduce the distortion of data for excessive correction. A L'Abbé plot was created to visualize 


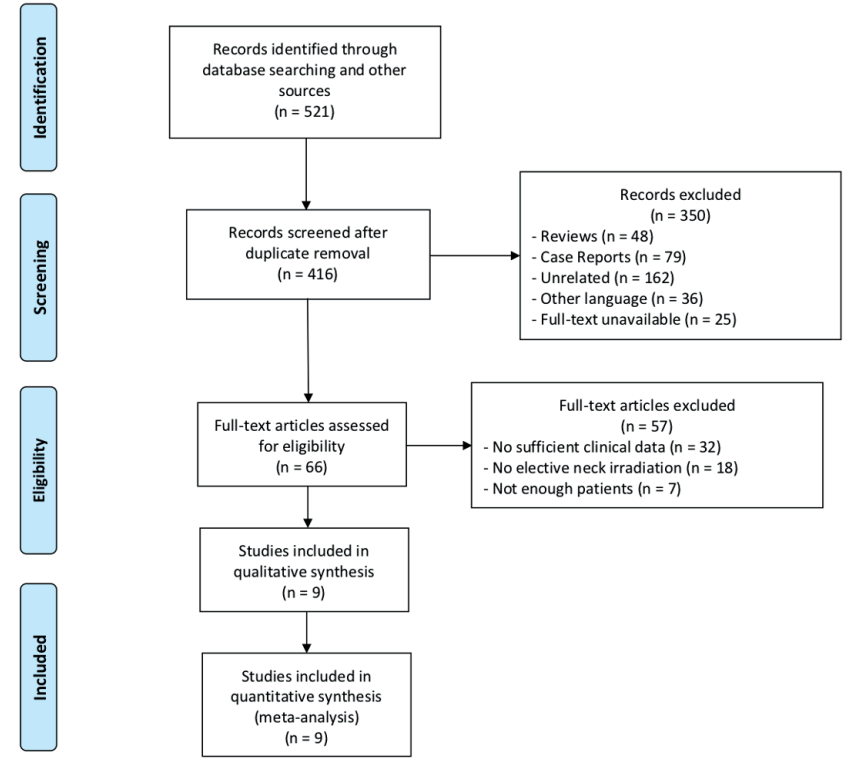

Figure 1. PRISMA flow diagram.

pooled effect estimate based on the RRR ${ }^{(17)}$. In particular, the event rate in the intervention group (ENI) was plotted against the event rate in the control group (observation) for each study, and the $\mathrm{N}$ of the study was signified by the size of the bubble in the plot. Peters' linear regression test was used to analyze the risk of publication bias ${ }^{(18)}$.

In order to compare the survival between the two treatment strategies, published Kaplan-Meier plots ${ }^{(19)}$ from each study were digitized using WebPlotDigitizer and survival probabilities and follow-up times extracted. The number of subjects at risk at different follow-up times, and the log hazard ratio (logHR) were calculated for each study using the method described by Tierney et al. ${ }^{(20)}$. The method proposed by Wan et al. ${ }^{(21)}$ was used to approximate the standard error. Finally, the pooled logHR was calculated comparing patients who underwent ENI and no elective neck treatment.

All the analyses were performed using the R software for statistical computing ( $R$ version 4.0.1). Statistical significance was defined as $p<0.05$.

\section{Results}

Literature search results

A flow chart of the study identification process is shown in Figure 1. After duplicate removal, a total of 416 potentially relevant publications were identified through database searching and other sources. After title and abstract review, 350 articles were rejected and full-texts of the remaining 66 papers were obtained for further review. After applying the aforementioned eligibility criteria, a total of 9 studies were included in the qualitative and quantitative synthesis ${ }^{(22-30)}$. The reasons behind the exclusions of the other studies are shown in Figure 1.

\section{Methodological quality and risk of bias of included studies} All of the included studies were of generally moderate quality and satisfied at least five of the eight NICE quality assessment tool items (Table 1). The main limitation is that all studies were retrospective. Moreover, the majority of studies ( $n=527$, 90.5\%) did not include an explicit statement that patients were recruited consecutively. Finally, only 118 (20.3\%) patients were enrolled in multicenter studies. The funnel plot generated for

Table 1. Quality Assessment of case series studies checklist from National Institute for Health and Clinical Excellence.

\begin{tabular}{|c|c|c|c|c|c|c|c|c|}
\hline Study, year & Multicenter? & Aim? & $\begin{array}{c}\text { Inclusion } \\
\text { and exclu- } \\
\text { sion criteria? }\end{array}$ & Outcome? & Prospective? & $\begin{array}{l}\text { Consecu- } \\
\text { tively? }\end{array}$ & $\begin{array}{l}\text { Main } \\
\text { findings? }\end{array}$ & $\begin{array}{l}\text { Outcomes } \\
\text { stratified? }\end{array}$ \\
\hline de Gabory et al., 2017 & Yes & Yes & Yes & Yes & No & No & Yes & Yes \\
\hline Herr et al., 2013 & Yes & Yes & Yes & Yes & No & No & Yes & Yes \\
\hline Hollen et al., 2015 & No & Yes & Yes & Yes & No & No & Yes & Yes \\
\hline Hu et al., 2020 & No & Yes & Yes & Yes & No & Yes & Yes & Yes \\
\hline Jiang et al., 2016 & No & Yes & Yes & Yes & No & No & Yes & Yes \\
\hline Modesto et al., 2013 & Yes & Yes & Yes & Yes & No & Yes & Yes & Yes \\
\hline Monroe et al., 2002 & No & Yes & Yes & Yes & No & No & Yes & Yes \\
\hline Song et al., 2019 & No & Yes & Yes & Yes & No & No & Yes & Yes \\
\hline Yin et al., 2015 & No & Yes & Yes & Yes & No & No & Yes & Yes \\
\hline
\end{tabular}

(1) Was the case series collected in more than one center (i.e., multi-center study? (2) Is the hypothesis/aim/objective of the study clearly described? (3) Are the inclusion and exclusion criteria (case definition) clearly reported? (4) Is there a clear definition of the outcomes reported? (5) Were data collected prospectively? (6) Is there an explicit statement that patients were recruited consecutively? (7) Are the main findings of the study clearly described? (8) Are outcomes stratified (e.g., by abnormal results, disease stage, patient characteristics)? 

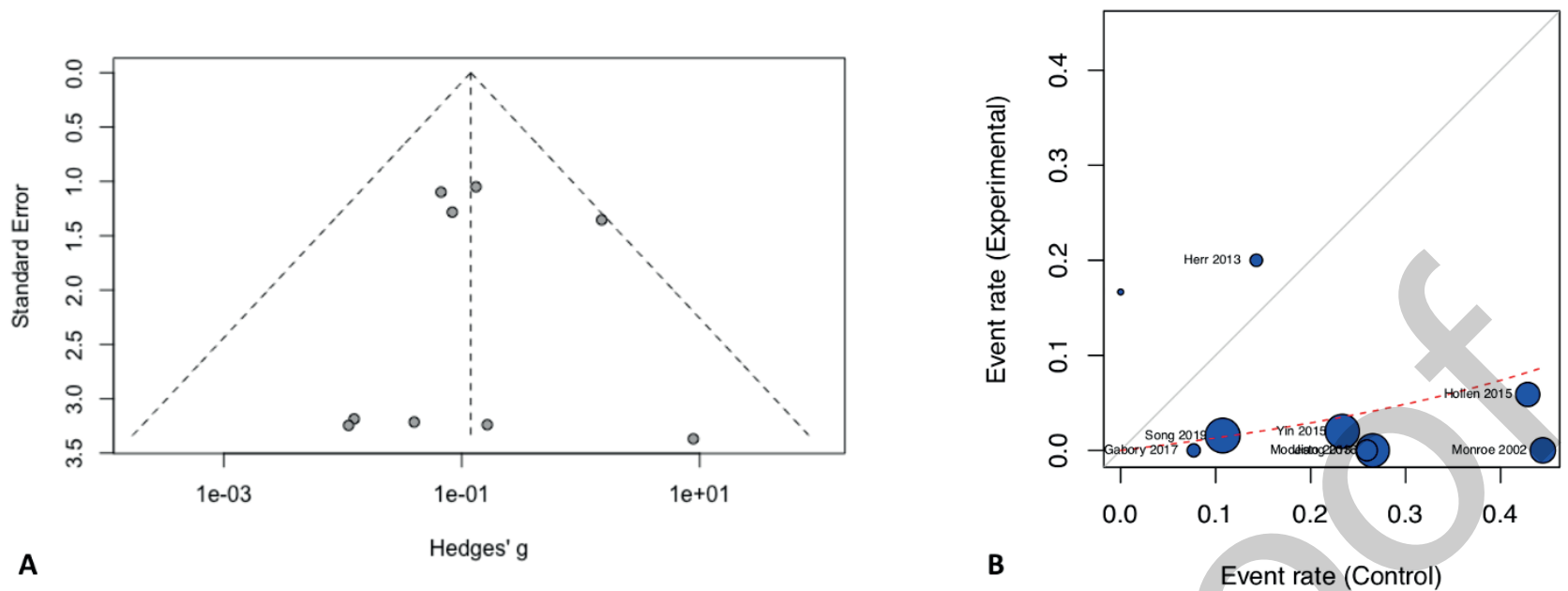

Figure 2. (A) Funnel plot for evaluation of publication bias. (B) L'Abbé plot showing the pooled effect estimate based on the RRR.

Table 2. Characteristics of included studies.

\begin{tabular}{|c|c|c|c|c|c|c|c|}
\hline Study, year & $\begin{array}{l}\text { No. } \\
\text { (Male) }\end{array}$ & Age (years) & FU (months) & Kadish classification & N classification & $\begin{array}{l}\text { Elective neck } \\
\text { irradiation }\end{array}$ & RRR \\
\hline $\begin{array}{l}\text { de Gabory et al., } \\
2017\end{array}$ & $53(32)$ & 54.3 (SD 19) & 45.4 (SD 26.5) & $\begin{array}{l}A(n=9) ; B(n=12) ; C \\
(n=25) ; D(n=7)\end{array}$ & $\begin{array}{l}\text { No }(n=46) ; N+ \\
(n=7)\end{array}$ & $\begin{array}{l}\text { ENI }(n=7) ; \text { None } \\
(n=39)\end{array}$ & $\begin{array}{l}\text { ENI, 0\% (0/7); None, } \\
7.7 \%(3 / 39)\end{array}$ \\
\hline $\begin{array}{l}\text { Herr et al., } \\
2013\end{array}$ & $22(11)$ & $\begin{array}{l}45.5 \text { (range } \\
11-77)\end{array}$ & $\begin{array}{l}73 \text { (range } \\
24-183 \text { ) }\end{array}$ & $\begin{array}{l}A(n=0) ; B(n=10) ; C \\
(n=12) ; D(n=0)\end{array}$ & $\begin{array}{l}\text { NO }(n=19) ; N+ \\
(n=3)\end{array}$ & $\begin{array}{l}\text { ENI }(n=5) \text {; None } \\
(n=14)\end{array}$ & $\begin{array}{l}\text { ENI, } 20 \%(1 / 5) ; \text { None, } \\
14.3 \%(2 / 14)\end{array}$ \\
\hline $\begin{array}{l}\text { Hollen et al., } \\
2015\end{array}$ & $26(16)$ & $\begin{array}{l}55 \text { (range } \\
3-82 \text { ) }\end{array}$ & $\begin{array}{l}78 \text { (range 3.6- } \\
260.4 \text { ) }\end{array}$ & $\begin{array}{l}A(n=0) ; B(n=7) ; C(n \\
=17) ; D(n=2)\end{array}$ & $\begin{array}{l}\text { NO }(n=24) ; N+ \\
(n=2)\end{array}$ & $\begin{array}{l}\text { ENI }(n=17) \\
\text { None }(n=7)\end{array}$ & $\begin{array}{l}\text { ENI, } 5.9 \%(1 / 17) ; \\
\text { None, } 42.9 \%(3 / 7)\end{array}$ \\
\hline $\begin{array}{l}\text { Hu et al., } \\
2020\end{array}$ & $12(10)$ & $\begin{array}{l}40 \text { (range } \\
14-77)\end{array}$ & 175 (range & $\begin{array}{l}A(n=0) ; B(n=4) ; C(n \\
=6) ; D(n=2)\end{array}$ & $\begin{array}{l}\text { NO }(n=10) ; N+ \\
(n=2)\end{array}$ & $\begin{array}{l}\text { ENI }(n=6) \text {; None } \\
(n=4)\end{array}$ & $\begin{array}{l}\text { ENI, } 16.7 \%(1 / 6) ; \\
\text { None, } 0 \%(0 / 4)\end{array}$ \\
\hline $\begin{array}{l}\text { Jiang et al., } \\
2016\end{array}$ & $71(44)$ & $\begin{array}{l}50.4 \text { (range } \\
12.9-77.4)\end{array}$ & $\begin{array}{l}80.8 \text { (range } \\
6-350)\end{array}$ & $\begin{array}{l}A(n=4) ; B(n=15) ; C \\
(n=51) ; D(n=1)\end{array}$ & $\begin{array}{l}\text { No }(n=71) ; N+ \\
(n=0)\end{array}$ & $\begin{array}{l}\text { ENI }(n=22) \\
\text { None }(n=49)\end{array}$ & $\begin{array}{l}\text { ENI, } 0 \%(0 / 22) ; \text { None, } \\
26.5 \%(13 / 49)\end{array}$ \\
\hline $\begin{array}{l}\text { Modesto et al., } \\
2013\end{array}$ & $43(24)$ & $\begin{array}{l}51 \text { (range } \\
8-80)\end{array}$ & 77 (N/A) & $\begin{array}{l}A(n=5) ; B(n=13) ; C \\
(n=16) ; D(n=9)\end{array}$ & $\begin{array}{l}\text { No }(n=34) ; N+ \\
(n=9)\end{array}$ & $\begin{array}{l}\text { ENI }(n=7) ; \text { None } \\
(n=27)\end{array}$ & $\begin{array}{l}\text { ENI, } 0 \%(0 / 7) ; \text { None, } \\
25.9 \%(7 / 27)\end{array}$ \\
\hline $\begin{array}{l}\text { Monroe et al., } \\
2002\end{array}$ & $22(11)$ & $\begin{array}{l}54 \text { (range } \\
3-82 \text { ) }\end{array}$ & $\begin{array}{l}43.2 \text { (range } \\
3.6-218.4 \text { ) }\end{array}$ & $\begin{array}{l}A(n=1) ; B(n=4) ; C(n \\
=15) ; D(n=2)\end{array}$ & $\begin{array}{l}\text { No }(n=20) ; N+ \\
(n=2)\end{array}$ & $\begin{array}{l}\text { ENI }(n=11) \\
\text { None }(n=9)\end{array}$ & $\begin{array}{l}\text { ENI, } 0 \%(0 / 11) ; \text { None, } \\
44.4 \%(4 / 9)\end{array}$ \\
\hline $\begin{array}{l}\text { Song et al., } \\
2019\end{array}$ & $217(161)$ & $\begin{array}{l}48.2 \text { (range } \\
7-86 \text { ) }\end{array}$ & $\begin{array}{l}58.9 \text { (range } \\
1.6-231.4 \text { ) }\end{array}$ & $\begin{array}{l}A(n=11) ; B(n=63) ; C \\
(n=111) ; D(n=32)\end{array}$ & $\begin{array}{l}\text { No }(n=185) \\
\text { N+ }(n=32)\end{array}$ & $\begin{array}{l}\text { ENI }(n=64) \\
\text { None }(n=121)\end{array}$ & $\begin{array}{l}\text { ENI, 1.6\% (1/64); } \\
\text { None, } 10.7 \%(13 / 121)\end{array}$ \\
\hline $\begin{array}{l}\text { Yin et al., } \\
2015\end{array}$ & $116(78)$ & $\begin{array}{l}36 \text { (range } \\
12-82 \text { ) }\end{array}$ & $\begin{array}{l}77 \text { (range } \\
4-223 \text { ) }\end{array}$ & $\begin{array}{l}A(n=1) ; B(n=23) ; C \\
(n=60) ; D(n=32)\end{array}$ & $\begin{array}{l}\text { No }(n=84) ; N+ \\
(n=32)\end{array}$ & $\begin{array}{l}\text { ENI }(n=50) \\
\text { None }(n=30)\end{array}$ & $\begin{array}{l}\text { ENI, } 2 \%(1 / 50) ; \text { None, } \\
23.3 \%(7 / 30)\end{array}$ \\
\hline
\end{tabular}

Abbreviations: FU follow-up, RRR regional recurrence rate, SD standard deviation, ENI elective neck irradiation.

the meta-analysis of the RRR is shown in Figure 2A. The plot is overall symmetrical, suggesting no obvious publication bias. Peter's test results also indicated no apparent publication bias (slope $=0.90, \mathrm{p}=0.40$ ).

\section{Studies description}

The general characteristics of the studies are shown in Table 2. A total of 582 (males: $65.6 \%, \mathrm{n}=382$ ) patients with a median age of 50.4 ( $n=582$, IQR $42.75-54.15)$ were included in this systematic review. The median follow-up was 73.0 months (n $=582$, IQR $44.3-77.5$ ). The Kadish stages of the patients were as follows: 31 stage $A(5.3 \%), 151$ stage $B(25.9 \%), 313$ stage $C$
(53.8\%), and 87 stage D (14.9\%). After the exclusion of patients presenting with metastatic cervical lymph node at diagnosis and three patients with no follow-up data, a total of 489 clinically node negative patients were included in the meta-analysis. The majority of patients $(n=300,61.3 \%)$ underwent no elective neck treatment, while the remaining patients underwent ENI ( $\mathrm{n}$ $=189,38.7 \%)$.

\section{Regional recurrence rate}

The cumulative RRR for clinically node negative patients who underwent ENI was 1.6\% ( $n=189,95 \% \mathrm{Cl}: 0.3 \%-3.9 \%, \mathrm{~T}^{2}=$ 0.0006). No significant variability was found across studies with 


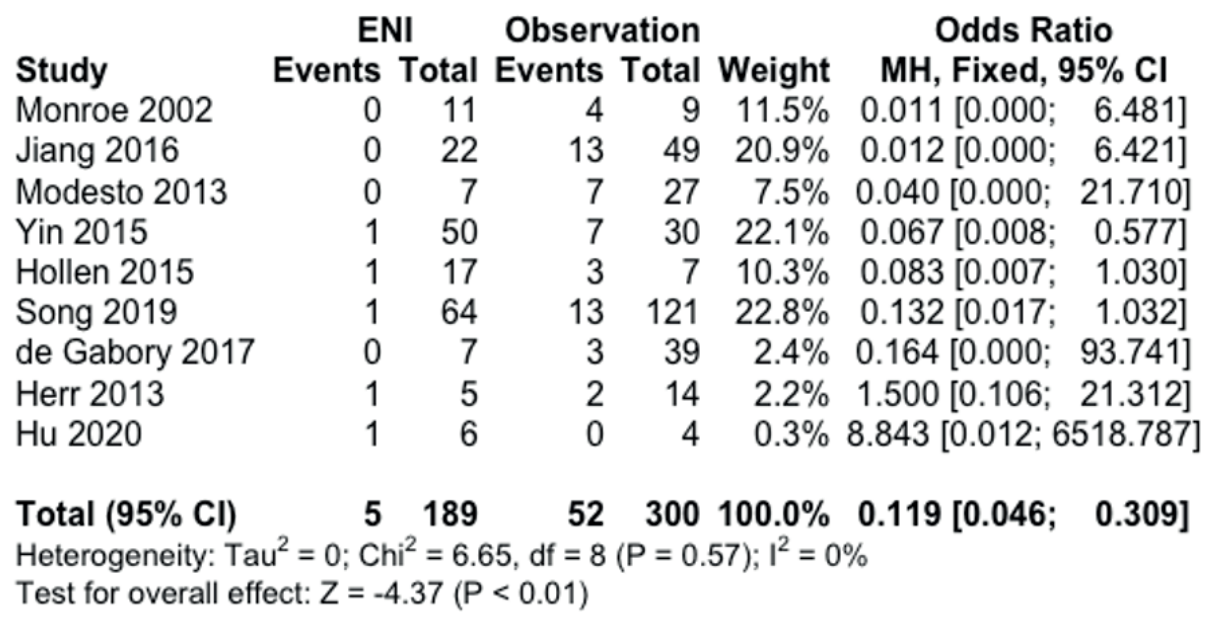

Figure 3. Forest plot showing cumulative odds ratios (ORs) of RRR and their $95 \%$ confidence intervals (Cls).

a $\mathrm{l}^{2}=4.3 \%$ (Q-statistic, $\left.\mathrm{p}=0.40\right)$. The cumulative RRR for clinically node negative patients who underwent observation was $18.8 \%$ $\left(\mathrm{n}=300,95 \% \mathrm{Cl}: 9.6 \%-30.2 \%, \mathrm{~T}^{2}=0.013\right)$, and a substantial heterogeneity was measured across studies $\left(I^{2}=60.9 \%\right.$; Q-statistic, $\mathrm{p}<0.05)$. The pooled OR was $0.12(95 \% \mathrm{Cl} 0.05-0.31 ; \mathrm{p}<0.05)$, indicating an $88 \%$ lower odds for regional nodal relapse in patients with ENI compared to those without. The pooled effect analysis for the cumulative RRR is shown in Figure 3. The L'Abbé plot showing the pooled effect estimate based on the RRR is shown in Figure 2B.

\section{Survival and distant metastases}

Only two of the included studies compared the survival between the two treatment strategies (ENI, $n=114$; observation, $n=151)$. Song et al. ${ }^{(29)}(n=185)$ measured a non-significant difference in terms of OS (79.9 \% vs. $88 \%)$ and DMFS (79.9 \% vs. $88 \%)$ at the 5-year follow-up, for ENI and observation respectively. Similarly, Yin et al. ${ }^{(30)}(\mathrm{n}=80)$ detected comparable oncological outcomes (OS, $77 \%$ vs. $62 \%$; DMFS, $77 \%$ vs. $73 \%$ ) in the two subgroups after 5 years.

Data from these studies were analyzed to calculate the pooled estimate. No difference was measured between ENI and observation, according to OS (logHR 0.18, 95\% Cl -1.37 - 1.73; $\mathrm{p}=0.82$ ) or DMFS (logHR -0.23, 95\% Cl-5.73-5.28; p = 0.93). Also, no heterogeneity was measured for either oncologic outcome (OS, $I^{2}=0 \%, Q$-statistic, $\mathrm{p}=0.36 ;$ DMFS, $\mathrm{I}^{2}=0 \%$, Q-statistic, $\mathrm{p}=0.73$ ).

\section{Discussion}

Due to the rarity of ENB and the consequent lack of large prospective studies, no defined guidelines are available to guide clinical practice ${ }^{(31)}$. For primary disease control, multimodality treatment regimens combining surgery with radiotherapy and/ or chemotherapy have been accepted as the gold standard(32-36). Even if definitive radiotherapy is rarely chosen for the primary treatment of ENB (e.g. patients unfit for surgery or early tumors), it continues to play a substantial role in multi-modality treatment, particularly in the adjuvant setting ${ }^{(5)}$. In fact, adjuvant radiation therapy improves local tumor control, particularly for high-grade and high-stage tumors. As already mentioned, the majority of patients suffering from ENB present with no clinically evident disease in the neck ${ }^{(2,6)}$. This is the main reason additional efforts should be made to define the optimal management of No neck, and further studies are indeed mandatory to assess the potential role of an elective treatment. According to the current literature, elective neck dissection (END) is rarely proposed for the management of ENB with a clinically node negative neck, but it is commonly used in the therapeutic treatment in case of clinically positive nodes ${ }^{(12)}$. In particular, no elective neck dissections were performed among the patients included in the present meta-analysis, and only therapeutic or salvage neck dissection was performed when appropriate. On the other hand, ENI was proposed for the management of the NO neck to improve patients' outcome. However, contradictory data, based on single institutions experiences, are available from the current literature ${ }^{(22-30)}$.

This is the first meta-analysis performed to analyze the role of ENI in clinically node negative ENB. In particular, we tried to assess the impact of ENI in regional disease control compared to observation. Moreover, we attempted to better define if ENI could potentially improve patients' survival. Our analysis showed a substantial reduction of the regional recurrence rate $(1.6 \%$ vs. $18.8 \%$; OR 0.12), while no difference was measured in terms of survival or distant metastases.

The decision to perform an elective neck treatment in head and neck tumors depends on the recurrence risk, the successful rate of salvage treatment, and the impact on survival ${ }^{(37)}$. In particular, an elective treatment of the neck aims to manage occult regional metastases at the time of diagnosis. However, current 
evidence does not allow for quantification of occult metastases rate due to the low number of patients who undergo elective neck dissection, and no data are provided in case of ENI. Moreover, some differences should be considered in the case of sinonasal tumors ${ }^{(38)}$, and particularly for the ENB. As mentioned above, regional metastases often occur late in the disease course ${ }^{(8)}$, and a regional failure could not be directly associated to occult metastases at the time of the primary treatment. As a consequence, the decision to perform ENI should not depend on the occult metastases rate, and other factors should be addressed.

Naples et al. ${ }^{(9)}$ performed a systematic review to quantify the risk of regional recurrence in ENB, measuring an overall RRR of approximately $15 \%$. However, no distinction was made considering the $\mathrm{N}$ classification at diagnosis, and therefore no stratified data were reported based on the management of the clinically N0 neck. Our results are consistent with the current literature data in terms of overall regional recurrence rate. In fact, the pooled risk of neck recurrence in our analysis was approximately $19 \%$ in clinically NO patients who did not undergo elective neck treatment. On the other hand, only $1.6 \%$ of patients treated with ENI showed a regional recurrence, demonstrating that ENI improves the regional disease control.

Another aspect that should be considered in the decision to perform an elective treatment of the neck is the salvage rate survival. As previously mentioned, a substantial proportion of regional metastases occurs late during patient follow-up, six or more months after the primary treatment. A previous meta-analysis ${ }^{(8)}$ showed an overall salvage failure of approximately $70 \%$. Even if a multimodality treatment approach composed of surgery plus radiotherapy improved the rate of successful neck salvage, the possibility to improve the regional disease control with an ENI should be considered to reduce the risk of salvage failure. Our pooled analysis of two large retrospective studies showed no impact of ENI in terms of survival.

As reported by current literature data, an increased mortality rate was measured in patients with recurrence in cervical lymph nodes when compared to those who never developed neck disease $(60 \% \text { vs. } 32 \%)^{(9)}$. Accordingly, a population-based study demonstrated the impact of nodal disease in terms of oncological outcome, measuring a critical reduction of the disease-specific survival in long-term follow-up ( $24 \%$ vs. $77 \%$ at 10-years) $)^{(1)}$. However, based on our results, the reduction of regional recurrence provided by ENI does not seem to reduce the risk of death or distant metastases. On the other hand, only two studies stratified patients by survival, reporting discordant results in terms of both OS and DMFS. Unfortunately, we were not able to determine the specific cause of death in the included studies. Some patients with regional recurrence had concurrent local and/or distance disease, which may have accounted for their death. Notably, we should take into account that these results may be confounded by a selection bias due to the retrospective study design ${ }^{(39)}$. In particular, ENI may select more advanced tumors leading to an underestimation of the oncological outcome. Therefore, the possibility to draw firm conclusions is limited from this perspective, and further prospective multicentric studies are needed to clarify this aspect.

This meta-analysis is subjected to some limitations. First, no stratification could be performed based on the Kadish classification $^{(40)}$, and no clear recommendation could be made based on the disease stage. In particular, only three studies ${ }^{(24,26,28)}$ ( $n=119,20.4 \%$ ) reported the number of regional recurrences stratified for the Kadish stage. In these studies, a total of $21(17.6 \%)$ patients presented a regional recurrence, and the majority (95\%) were classified as Kadish C stage. However, these studies did not stratify the stage of patients in the two subgroups (ENI and observation) to calculate the stratified regional recurrence rate. The irradiation of the neck is warranted in case of Kadish D tumors presenting with regional metastases, as a therapeutic approach. Moreover, Kadish D tumors with distant metastases at presentation require customized management, and the decision to perform ENI depends on the multimodality treatment regimen. Hence, the discussion should be focused on the remaining tumor stages. Particularly, we should consider that only a minority of included patients (5\%) suffered from a Kadish stage A tumor. Therefore, our results may not be applied to these patients. Moreover, Naples et al. ${ }^{(9)}$ measured no neck recurrence in this subset of patients. Stage $B$ and stage $C$ tumors are therefore the true potential recipients of ENI, but only further research could customize the elective treatment of these tumors in terms of radiation dose and volume.

Second, the Hyams grading was reported only in one study (22), but the regional recurrence and survival were not stratified. As a consequence, no distinction could be made between low- and high-grade tumors based on current literature data. A previous meta-analysis ${ }^{(41)}$ demonstrated that the tumor grade predicts the risk of neck metastases, in addition to distant metastases and patient survival. However, further studies are needed to determine if only high-grade tumors could benefit from ENI. Third, all included studies were retrospective cohort studies, that are inherently prone to various biases especially regarding patient selection and outcome assessment. Moreover, some studies were not specifically designed to assess the regional disease control, analyze the risk factors for regional metastases, nor their impact on patient survival. This may introduce several biases, such as selection and recall bias. However, ENB represents a rare entity, and the possibility to merge data from multiple studies allows us to perform cumulative analysis of larger samples, improving the robustness of the evidence.

Finally, further studies must be conducted to better define the lymph nodes levels which should be irradiated electively. No 
data are currently available on the specific neck levels site of regional recurrence. Moreover, data from included studies were not stratified according to ipsilateral or bilateral ENI. No clear recommendations could be defined from this perspective, and the irradiation modality should be based on specific institution regimen.

\section{Conclusion}

This meta-analysis showed a significant reduction of regional recurrence in clinically node negative ENB treated with ENI. No advantage was measured in terms of survival or distant metastases for patients who underwent ENI, but the quality of evidence is too low to draw firm conclusions from this perspective.

ENI should be recommended to improve the regional disease control in at least Kadish B and Kadish C stages. Further prospective studies should be designed to understand if ENI could be avoided in early stage and low-grade tumors, as well as to define the best radiotherapy regimen in terms of dose and target volume.

\section{Authorship contribution}

ADV: Study design, manuscript development, review of final manuscript. AC: Study design, data collection and analysis, manuscript development, review of final manuscript. DS: Data collection, review of final manuscript. ER: Data collection, review of final manuscript. CF: Study design, review of final manuscript. GM: Study design, review of final manuscript. MS: Supervision, review of final manuscript. GS: Supervision, manuscript development, review of final manuscript.

\section{Conflict of interest}

None.

\section{Financial disclosure}

None.

\section{References}

1. Jethanamest D, Morris LG, Sikora AG, Kutler DI. Esthesioneuroblastoma: a populationbased analysis of survival and prognostic factors. Arch Otolaryngol Head Neck Surg 2007;133(3):276-80.

2. Ferlito A, Rinaldo A, Rhys-Evans PH Contemporary clinical commentary: esthesioneuroblastoma: an update on management of the neck. Laryngoscope 2003;113(11):1935-8.

3. Vartanian RK. Olfactory neuroblastoma: an immunohistochemical, ultrastruc tural, and flow cytometric study. Cancer 1996;77(9):1957-9.

4. Fu TS, Monteiro E, Muhanna N, Goldstein DP de Almeida JR. Comparison of outcomes for open versus endoscopic approaches for olfactory neuroblastoma: A systematic review and individual participant data meta-analysis. Head Neck 2016;38 Suppl 1:E2306-2316.

5. Foote RL, Morita A, Ebersold MJ, et al Esthesioneuroblastoma: the role of adjuvant radiation therapy. Int J Radiat Oncol Biol Phys 1993;27(4):835-42.

6. Rinaldo A, Ferlito A, Shaha AR, Wei WI, Lund VJ. Esthesioneuroblastoma and cervical lymph node metastases: clinical and therapeutic implications. Acta Otolaryngol 2002;122(2):215-21.

7. Dulguerov P, Allal AS, Calcaterra TC. Esthesioneuroblastoma: a meta-analysis and review. Lancet Oncol 2001;2(11):68390.

8. Gore MR, Zanation AM. Salvage treatment of late neck metastasis in esthesioneuroblastoma: a meta-analysis. Arch Otolaryngol Head Neck Surg 2009;135(10):1030-4.

9. Naples JG, Spiro J, Tessema B, Kuwada C, Kuo C-L, Brown SM. Neck recurrence and mortality in esthesioneuroblastoma: Implications for management of the NO neck. Laryngoscope 2016;126(6):1373-9.

10. Loy $A H$, Reibel JF, Read PW, et al. Esthesioneuroblastoma: continued follow-up of a single institution's experience. Arch Otolaryngol Head Neck Surg 2006:132(2):134-8.

11. Dias FL, Sa GM, Lima RA, et al. Patterns of failure and outcome in esthesioneuroblastoma. Arch Otolaryngol Head Neck Surg 2003;129(11):1186-92

12. Zanation AM, Ferlito A, Rinaldo A, et al. When, how and why to treat the neck in patients with esthesioneuroblastoma: a review. Eur Arch Otorhinolaryngol 2010;267(11):1667-71.

13. Liberati A, Altman DG, Tetzlaff J, et al. The PRISMA statement for reporting systematic reviews and meta-analyses of studies that evaluate health care interventions: explanation and elaboration. PLoS Med 2009;6(7):e1000100

14. National Institute for Health and Care Excellence. Methods for the Development of NICE Public Health Guidance. London: National Institute for Health and Care Excellence (NICE); 2012.

15. Jackson D, White IR, Riley RD. Quantifying the impact of between-study heterogeneity in multivariate meta-analyses. Stat Med 2012;31(29):3805-20.

16. Veroniki AA, Jackson $D$, Viechtbauer $W$, et al. Methods to estimate the between-study variance and its uncertainty in meta-analysis. Res Synth Methods 2016;7(1):55-79.

17. L'Abbé KA, Detsky AS, O'Rourke K. Metaanalysis in clinical research. Ann Intern Med 1987;107(2):224-33.

18. Peters $J$, Sutton AJ, Jones DR, Abrams KR, Rushton L. Comparison of two methods to detect publication bias in meta-analysis JAMA 2006;295(6):676-80.

19. Efron B. Logistic Regression, Survival Analysis, and the Kaplan-Meier Curve. null 1988;83(402):414-25.

20. Tierney JF, Stewart LA, Ghersi D, Burdett S, Sydes MR. Practical methods for incorporating summary time-to-event data into metaanalysis. Trials 2007;8:16.

21. Wan X, Wang W, Liu J, Tong T. Estimating the sample mean and standard deviation from the sample size, median, range and/or interquartile range. BMC Med Res Methodol 2014;14:135

22. de Gabory L, Verillaud B, Rumeau C, et al. Multicenter assessment of exclusive endoscopic endonasal approach for the treatment of 53 olfactory neuroblastomas. Head Neck 2018;40(5):1000-7

23. Herr MW, Sethi RKV, Meier JC, et al. Esthesioneuroblastoma: an update on the massachusetts eye and ear infirmary and massachusetts general hospital experience with craniofacial resection, proton beam radiation, and chemotherapy. J Neurol Surg B Skull Base 2014;75(1):58-64.

24. Hollen TR, Morris CG, Kirwan JM, et al Esthesioneuroblastoma of the nasal cavity. Am J Clin Oncol 2015;38(3):311-4.

25. Hu W, Hu J, Gao J, et al. Intensity-modulated particle beam radiation therapy in the management of olfactory neuroblastoma. Ann Transl Med 2020;8(15):926.

26. Jiang W, Mohamed ASR, Fuller CD, et al The role of elective nodal irradiation for esthesioneuroblastoma patients with clinically negative neck. Pract Radiat Oncol 2016;6(4):241-7.

27. Modesto A, Blanchard P, Tao YG, et al. Multimodal treatment and long-term outcome of patients with esthesioneuroblas- 
toma. Oral Oncol 2013;49(8):830-4.

28. Monroe AT, Hinerman RW, Amdur RJ, Morris CG, Mendenhall WM. Radiation therapy for esthesioneuroblastoma: rationale for elective neck irradiation. Head Neck 2003;25(7):529-34.

29. Song X, Huang C, Wang S, Yan L, Wang J, Li Y. Neck management in patients with olfactory neuroblastoma. Oral Oncol 2020;101:104505

30. Yin Z, Luo J, Gao L, et al. Spread patterns of lymph nodes and the value of elective neck irradiation for esthesioneuroblastoma. Radiother Oncol 2015;117(2):328-32.

31. National Comprehensive Cancer Network. (2020). Head and Neck Cancers (version 1.2021). https://www.nccn.org/professionals/physician_gls/pdf/head-and-neck.pdf.

32. Chao KS, Kaplan C, Simpson JR, et al. Esthesioneuroblastoma: the impact of treatment modality. Head Neck 2001;23(9):74957.

33. McElroy EA, Buckner JC, Lewis JE. Chemotherapy for advanced esthesioneuroblastoma: the Mayo Clinic experience. Neurosurgery 1998;42(5):1023-7.

34. Levine PA, Gallagher R, Cantrell RW.
Esthesioneuroblastoma: reflections of a 21-year experience. Laryngoscope 1999;109(10):1539-43.

35. Resto VA, Eisele DW, Forastiere A Zahurak M, Lee DJ, Westra WH. Esthesioneuroblastoma: the Johns Hopkins experience. Head Neck 2000;22(6):550-8.

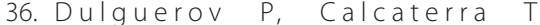
Esthesioneuroblastoma: the UCLA experience 1970-1990. Laryngoscope 1992;102(8):843-9.

37. Wei WI, Ferlito A, Rinaldo A, et al Management of the NO neck--reference or preference. Oral Oncol 2006;42(2):115-22.

38. De Virgilio A, Costantino A, Canzano F, et al. Regional disease control in sinonasal mucosal melanoma: Systematic review and meta-analysis. Head Neck 2021;43(2):70515.

39. Hernán MA, Hernández-Díaz S, Robins JM. A structural approach to selection bias. Epidemiology 2004;15(5):615-25.

40. Morita A, Ebersold MJ, Olsen KD, Foote RL, Lewis JE, Quast LM. Esthesioneuroblastoma: prognosis and management. Neurosurgery 1993;32(5):706-14.

41. Goshtasbi K, Abiri A, Abouzari M, et al
Hyams grading as a predictor of metastasis and overall survival in esthesioneuroblastoma: a meta-analysis. Int Forum Allergy Rhinol 2019;9(9):1054-62.

Andrea Costantino, MD

Department of Biomedical Sciences

Humanitas University

Via Rita Levi Montalcini 4

20090 Pieve Emanuele

Milan

Italy

Tel.: +3902 82248282

Fax: +3902 82248282

E-mail:

andrea.costantino94@gmail.com

ORCID ID: 0000-0001-5551-7785 